\title{
Patrimônio imobiliário convertido em HERANÇA CULTURAL: A CASA COMO ESPAÇO DE TRANSMISSÃO DO GOSTO ERUDITO EM FAMílIAS DA ELITE CULTURAL PAULISTANA
}

\begin{abstract}
RESUMO: Este artigo investiga a transmissão da herança cultural entre membros de famílias de elite, cujos pais foram encomendantes de casas de arquitetura de autor, isto é, projetadas por arquitetos reconhecidos e valorizados por sua assinatura. Apoiando-se, prioritariamente, em um conjunto de entrevistas feitas com filhos, procurou-se restituir a dinâmica de aquisição e conservação dos diversos capitais no interior desses grupos. A análise dos casos permite expor a continuidade da transmissão cultural e do gosto artístico a partir da experiência doméstica. Para esses membros de grupos culturalmente privilegiados, que desde a infância tiveram a experiência de habitar em espaços domésticos dotados dos mais prestigiosos bens materiais - livros, obras de arte, mobiliários de design, objetos de coleção, relíquias familiares -, a casa foi espaço constituidor de uma relação cultivada com a cultura. A herança cultural erudita se manifesta nos mais diversos domínios da vida, na hexis corporal e nos valores internalizados, nas práticas culturais e nas escolhas profissionais.
\end{abstract}

PALAVRAS-CHAVES: Elites. Habitação. Gosto erudito. Herança.

\section{Introdução}

Um dos esforços que tem renovado os estudos de elites é o cruzamento com a sociologia do gosto, tendo o objetivo de entender de que forma os grupos dominantes, na diversidade de suas riquezas e modos de exercício de poder, produzem ethos

\footnotetext{
USP - Universidade de São Paulo. Faculdade de Filosofia Letras e Ciências Humanas. São Paulo SP - Brasil. 05508010 - camila.rosatti@gmail.com. https://orcid.org/0000-0001-6049-5904.
} 
próprio, conservam suas visões de mundo e inculcam preferências realizando uma transmissão bem-sucedida de valores e práticas entre gerações (BOURDIEU, 1996; SAINT-MARTIN, 2002; ALMEIDA \& NOGUEIRA, 2002; CHARLE, 2006; PINÇON \& PINÇON-CHARLOT, 2009; PULICI \& FERNANDES, 2019). Este artigo pretende contribuir com tais estudos investigando, a partir da noção de gosto e estilo de vida, o espaço por excelência da socialização familiar, a casa ${ }^{1}$. A partir dela, é possível tratar a questão da transmissão da herança tanto em termos materiais quanto em termos culturais, entendendo que a posse e a conservação de patrimônio imobiliário e patrimônio simbólico estão na base da reprodução familiar e social dos grupos dominantes.

De modo geral, as moradias podem ser classificadas entre os bens mais dispendiosos e prestigiosos de investimento das classes dominantes. Por uma via muito particular e pouco usual, o presente estudo se aproxima de outras pesquisas da área da sociologia das elites no Brasil que têm focalizado os grupos dominantes, sejam nomeados como elites ou alta burguesia ${ }^{2}$, tratando as chamadas casas de arquitetura de autor. Entretanto, em vez de focalizar as classes dirigentes, investi na investigação de frações dominantes mais amplas, que exercem alguma modalidade de influência ou notoriedade no âmbito cultural; portanto, não exclusivamente aquelas que detêm poder econômico ou político.

Ao considerar que a adoção de estilos de vida exclusivos se expressa exemplarmente por escolhas em matéria de habitação e dos modos de morar, segui as trilhas abertas por pesquisas que analisaram as estratégias de distinção de frações dominantes a partir do espaço residencial (BOURDIEU \& DELSAUT, 1975; DURAND, 1989; MENSION-RIGAU, 1990; MONTEIRO, 1998; ELIAS, 2001; TRIGO, 2001; PINÇON \& PINÇON-CHARLOT, 2005; HOMEM, 2010; PULICI, 2010). Um ponto comum a destacar nesses trabalhos é a entrada empírica: a moradia foi utilizada como via privilegiada de acesso a grupos exclusivos e muito fechados, cuja aproximação não ocorre tão facilmente.

Neste artigo, trato especificamente de encomendantes de residências ligadas ao modernismo arquitetônico paulista, movimento estético que floresceu predominantemente na capital em torno da metade do século XX. Para essa clientela, vale assinalar, a adoção da estética modernista se fez com a ajuda de uma figura de intermediação cultural central para a disseminação desse gosto: os arquitetos modernos,

\footnotetext{
1 Este artigo se apoia em material empírico coletado ao longo de minha pesquisa de doutorado, durante a qual recebi bolsa da Fundação de Amparo à Pesquisa do Estado de São Paulo (nº 2012/14020-0 e 2014/10276-6). Atualmente, desenvolvo pesquisa de pós-doutorado financiada pela mesma agência de fomento ( $n^{\circ} 2017 / 11458-9$ e 2018/23451-1), a quem registro meus agradecimentos.

2 Aí se incluem importantes estudos que enfocam o trabalho de dominação simbólica exercido por agentes em diversas esferas, entre as quais, cultural, religiosa, artística, intelectual, científica e acadêmica (MICELI, 1996; CORADINI, 2001; ALMEIDA, CANEDO \& GARCIA, 2004; HEINZ et al., 2006; GRYNSZPAN \& GRILL, 2011).
} 


\section{Patrimônio imobiliário convertido em herança cultural: a casa como espaço de transmissāo do gosto erudito em familias da elite cultural paulistana}

que desempenharam com obstinação o papel de prescritores e legitimadores da nova estética. Nesse caso, a contratação de profissionais destacados no campo artístico local serviu para que a clientela tivesse acesso a novos códigos formais ligados à vanguarda. Como é comumente encontrado nas estratégias de dominação cultural, a intermediação do profissional do gosto, aquele que dispõe de autoridade para prescrever, foi decisiva para afirmação de um estilo de vida ao mesmo tempo cultivado e ousado, marcadamente diferente da maioria das moradias de classe média alta paulistana que, nesse período, entre as décadas de 1940 e 1960, adotavam arquitetura mais tradicional, ou, quando modernas, elegiam expressão estética menos radical. Disso decorre um dos pontos no cerne da sociologia do gosto, a questão da diferenciação social. As escolhas são também recusas, ou seja, são tanto demonstração de preferências pessoais quanto demarcação em relação ao gosto dos outros e, portanto, instituição de distância social segura, mesmo que simbólica.

Investigando as escolhas estéticas em relação aos modos de morar, assumimos o pressuposto de que as preferências artísticas possibilitam situar as famílias no espaço social a partir do espaço das preferências culturais, tal como desenvolvida por Pierre Bourdieu, em A distinção: Crítica social do julgamento (2007). Mais amplamente, tendo em vista outros trabalhos do autor francês, a casa é um bem muito particular que exprime de forma decisiva e profunda o lugar social dos proprietários. Como é investimento ao mesmo tempo econômico e afetivo, está diretamente ligada a visões de mundo e estratégias que orientam escolhas matrimoniais, estéticas, geográficas e financeiras, por exemplo, em decisões simples e complexas, tais como: com quem casar, onde se fixar, alugar ou construir, apartamento ou residência unifamiliar; atributos que conferem alta carga simbólica a esse empreendimento. E ainda em termos materiais, é configuração espacial que expressa escolhas formais e estéticas, visíveis na fachada, na planta, nos usos dos espaços e nas escolhas de decoração. Ou seja, a casa é tanto escolha estética, entesouramento, investimento de dinheiro, quanto define um projeto de reprodução biológica e social, de perpetuação do grupo, assegurando a transmissão do patrimônio familiar que é também uma cultura de classe, com seus gostos e estilos de vida (BOURDIEU, 1979, 1990, 1993, 1999, 2006).

Ademais, a habitação se mostra uma entrada pertinente para a análise das expressões de gosto, pois a despeito de ser um ambiente privado e corriqueiro e, no senso comum, visto como regido por decisões íntimas ou banais, ela expressa, antes de tudo, uma maneira de estar no mundo que é da ordem do prosaico, rotineiro e, assim, persistente. $\mathrm{O}$ fato de ser um espaço de investimento pessoal, cotidiano, profundo e duradouro faz com que os modos de morar ultrapassem a escala do indivíduo e da família e se cristalizem em configurações históricas e culturais (FREYRE, 2004, 2006; ROCHE, 2000; BRAUDEL, 2005; ELIAS, 2001; CERTEAU, 2013). 
Abordando a casa como espaço de mediação entre o indivíduo e a sociedade, Norbert Elias e Pierre Bourdieu, guardadas as diferenças entre os dois autores, mostram que a habitação, por ser espaço de socialização primária, está na base da formação dos modos de ver, sentir e classificar o mundo. É nesse espaço de constituição e reprodução da família que os membros do grupo interiorizam um conjunto amplo de condutas e escolhas, conscientes e inconscientes, que se impõem quase como segunda natureza. Desse modo, para esses dois autores, o gosto e os modos de vida estão ligados a aquisições culturais hierarquizadas que se enraízam desde a experiência cotidiana mais ordinária e material - por exemplo, nos gestos e na hexis corporal, nas maneiras de se vestir, se alimentar, se portar à mesa, nas práticas de decoração e organização da casa -, até nos domínios mais puros e transcendentais do espírito, associados, por exemplo, ao deleite com música erudita, artes plásticas, alta literatura, cinema de autor etc., o que faz que se torne um marcador social potente de diferenciação entre grupos.

É a partir dessas balizas teóricas que o presente estudo buscou cruzar as escolhas em torno da moradia e constituição de grupos de elites para investigar hereditariedade cultural e transmissão do gosto, tendo em vista o espaço da casa, notadamente, desde exemplares de arquitetura erudita, via de entrada que permite analisar um segmento específico das classes dominantes brasileiras: as frações da elite paulistana ligada a setores culturais e artísticos.

\section{Fontes e metodologia}

Alguns detalhes contextualizando os dados empíricos e a abordagem metodológica são necessários. Em relação às fontes, o estudo se apoia em material empírico diversificado coletado ao longo de minha pesquisa de doutorado, que desta vez recebeu tratamento sob novo enfoque analítico, incorporando sobretudo reflexões da sociologia das elites ${ }^{3}$. Esse material inclui entrevistas realizadas com moradores em suas próprias residências modernas ou fora delas, como local de trabalho e residência atual.

Entre 2012 e 2015, no andamento da pesquisa de campo, entrei em contato com filhos dos encomendantes, alguns herdeiros dessas moradias, com intuito de entrevistá-los para, inicialmente, conhecer as condições de encomenda dos projetos residenciais, tal como imaginadas e planejadas por seus pais, no período entre as décadas de 1940 e 1960. O objetivo central era levantar dados sobre a trajetória profissional dessa clientela, o envolvimento com a arquitetura moderna e os círculos sociais em que estavam envolvidos. Inspirada em trabalhos etnográficos

\footnotetext{
3 A descrição detalhada dos materiais e métodos está no capítulo 1 da tese de doutorado (ROSATTI, 2016).
} 


\section{Patrimônio imobiliário convertido em herança cultural: a casa como espaço de transmissão do gosto erudito em famílias da elite cultural paulistana}

da sociologia das elites francesas, fiz uso de entrevistas semidiretivas de longa duração com os herdeiros dessas famílias (MENSION-RIGAU, 1990; LE WITA, 1988; PINÇON \& PINÇON-CHARLOT, 2007) ${ }^{4}$.

Os oito depoimentos, recolhidos em longas conversas que chegaram a durar entre 4 e 6 horas, foram realizados, em sua maioria, no local de moradia dos filhos. Ainda que tenhamos consciência da limitação do número de casos, a escolha metodológica oferece a vantagem de se extrair da observação de campo e da própria dinâmica de interação social da entrevista, na qual discursos e práticas específicas permitem nuançar a caracterização dos grupos de elite. Tendo em vista essa interação, aponto algumas notas sobre a pesquisa sociológica entre dominantes.

De partida, convém citar que as tentativas de acesso aos moradores se deram por diferentes formas, seja procurando-os a partir dos sobrenomes de família via internet (principalmente pelas mídias sociais, como o Facebook), seja entrando em contato a partir de indicações de conhecidos, que passavam e-mail e telefone. Ou ainda, uma vez munida do endereço da residência, ia até o local e, sem aviso prévio, anunciava a pesquisa à campainha. Quando entrava em contato por e-mail, explicando o estudo, ressaltava que se tratava de levantar questões sobre a arquitetura moderna a partir do ponto de vista do cliente. Isso fez com que a grande maioria se mostrasse simpática e acolhesse o estudo, por certo tomando-o como chance de recuperar a memória familiar. Eles ficaram lisonjeados em serem incluídos na lista de entrevistados e consideravam importante que fosse dado o devido destaque ao encomendante, pelo papel decisivo que atribuíam aos pais como apoiadores fundamentais do movimento arquitetônico moderno paulista.

Esse material de campo foi complementado com reportagens de revistas voltadas para arquitetura e estilo de vida, matérias em jornais paulistas, biografias e autobiografias publicadas pelos próprios encomendantes ou filhos, além de colunas sociais, homenagens divulgadas em sites, memórias, boletins necrológicos etc, material com conteúdo biográfico indicador de que são personagens consagrados ou com experiência a ser compartilhada, confirmando o lugar de destaque cultural alcançado. Quando produzido por familiares ou membros da mesma linhagem (herdeiros na família ou sócios em empresa), esse material aponta para as estratégias de visibilidade e gestão da memória mobilizadas pelos autointeressados, aliás, recursos de legitimação cultural frequente em grupos dominantes.

Tanto as fotografias do interior doméstico, disponíveis nesses documentos, quanto as visitas às residências, realizadas junto às entrevistas, forneceram informações estéticas expressivas sobre as formas de morar e decorar. Com elas, pude observar diversas escolhas quanto à disposição e ao arranjo da moradia a

\footnotetext{
4 No Brasil, no âmbito da sociologia das elites, dois estudos podem ser destacados na mesma linha para frações paulistanas (PULICI, 2010) e frações recifenses (MACIEL, 2018).
} 
partir, por exemplo, de mobiliário, objetos de decoração, revestimentos e materiais de acabamento, presença de obras de arte, tapetes, cortinas, objetos de viagens, retratos de família, instrumentos musicais, estantes de livros, todos visivelmente acessíveis nos espaços em que me receberam ou ao olhar do fotógrafo. As plantas do projeto arquitetônico foram outro documento consultado, o qual forneceu elementos significativos quanto ao programa de necessidades, à distribuição e uso dos espaços (cômodos existentes, área, tipologia). Cumpre sinalizar que, embora as reportagens na mídia e o material gráfico seja um dado expressivo do padrão econômico, das escolhas estéticas dos proprietários e de suas formas de morar, estas não foram aqui referenciadas para que os moradores não sejam reconhecidos, uma vez que as entrevistas foram concedidas sob condição de anonimato.

Nas entrevistas, as questões colocadas tinham o objetivo de reconstituir a trajetória social do encomendante da residência a partir de informações sobre origens sociais (local de nascimento e se imigrante, razões da vinda ao Brasil), formação escolar e universitária, atuação profissional, engajamento político, círculos de amizades, práticas culturais e de lazer (gosto musical, literário e artístico, colecionismo, frequentação de exposições e concertos, viagens etc.). Tendo em vista que a construção da casa, na maioria das vezes, representa um projeto de constituição de família, notadamente associada ao casamento (que o célebre "quem casa quer casa" registra) e de reprodução social (fixado exemplarmente nos ditados: "educação se traz de casa", "educação vem de berço"), um conjunto de questões versava sobre escolhas matrimoniais e filhos (origens sociais da parceira, número de filhos, formação escolar, universitária, profissão, práticas culturais). O propósito foi também de fornecer informações sobre o perfil sociocultural dos membros e as estratégias associadas à transmissão do patrimônio.

\section{Entrevistar frações dominantes: algumas observações sobre pesquisa de campo}

As entrevistas realizadas em residências modernas herdadas pelos filhos permitiram aprofundar a reflexão metodológica a partir da interação com os informantes, tendo em vista que o roteiro de perguntas pré-definido, ainda que o propósito fosse acessar de modo mais pontual dados sociais e práticas culturais, abriu margem para que os entrevistados narrassem fatos e anedotas familiares, a partir das quais foi possível observar os modos como se representam e falam sobre si.

Quanto a isso, é preciso levar em conta os limites dessa estratégia de pesquisa, chamando a atenção para o fato de que, sendo narrativas produzidas pelos herdeiros, com distância temporal da construção da moradia, os relatos, evidentemente, trazem informações aproximativas ou muito vagas e podem carregar visão reelaborada, e 


\section{Patrimônio imobiliário convertido em herança cultural: a casa como espaço de transmissáo do gosto erudito em famílias da elite cultural paulistana}

até mesmo encantada, sobre a residência em que moraram. Em alguns casos, por exemplo, mesmo quando a residência havia sido projetada e construída ainda quando os entrevistados eram bebês, ou até antes do nascimento, ainda assim demonstravam conhecer as razões da encomenda ou alguma historieta, por exemplo, referente a acordos e desacordos com arquiteto ilustre, o que mostra que se tratou de uma narrativa transmitida e celebrada como história familiar, formando uma espécie de memória genealógica em torno da casa. Em outros dois casos registrados, quando os entrevistados tinham morado na casa apenas nos primeiros anos de vida, tendo se mudado em razão de separação dos pais e por razões profissionais da família, a narrativa sobre a encomenda e a vivência na casa ganharam ares de exaltação e encantamento: espaços aumentados e as soluções do arquiteto muito valorizadas com um relato ainda maravilhado com aquilo que avaliavam como excepcionalidade da moradia.

Vale destacar, também, que a entrevista em situações domésticas proporcionou momentos de descontração carregados de conteúdo em que apareceram informações das mais amplas relativas às dimensões de gosto, bastante sugestivas das propriedades sociais dos informantes, como o cafezinho, servido em louças herdadas da família acompanhado de biscoitos finos, e a oferta de um bolo caseiro, recémpreparado pela empregada doméstica seguindo a receita tradicional da avó. Esses momentos espontâneos, ainda que pareçam pouco relevantes, revelam o volume e o tipo de capital cultural possuído, recursos transmutados na linguagem e nas mais variadas práticas, entre as quais, os modos elegantes e desenvoltos de servir, se portar à mesa e de se alimentar.

Pude observá-los em diversos outros momentos das visitas: ao me mostrarem a decoração, destacarem fotografias dos antepassados e algumas relíquias transmitidas de geração em geração, nos discursos de apresentação da casa, nas maneiras de falar sobre a família e de se referir a seus membros e no interesse, quase sem esforço, em apresentar uma genealogia gloriosa ou heroica da família, muitas vezes destacando engajamento político, intelectual e artístico dos pais e pessoas do convívio. Em alguma dessas situações, dada a possibilidade de circular pela casa, conduzida pelo proprietário, fui colocada na posição de comprovar os relatos e os bens mencionados nas conversas.

A interação durante a entrevista, por vezes embaraçosa, por vezes fluida e desenvolta, aponta elementos que permitem refletir sobre as condições de realização da pesquisa e o acesso às famílias de elite. É importante, pois, ainda que de modo sintético, abordar minha presença no campo, mais especificamente, minha relação com os entrevistados, questão sempre difícil e delicada quando se trata de estudos em grupos de elite; como se sabe, são mais fechados e discretos em relação à explicitação de seus modos de vida e seu patrimônio ou, quando o fazem, ocorre o risco de fazer do pesquisador um enunciador de seus argumentos (LE WITA, 1988; PINÇON \& PINÇON-CHARLOT, 2007; LIMA, 2007). 
Algumas situações recorrentes mostram um pouco das dificuldades próprias à pesquisa em grupos de elite; no caso, de famílias da elite cultural. Diversas vezes me lançaram perguntas sobre conhecimentos específicos ligados a cultura, arte, viagens, escritores, livros e arquitetura. Quase como um quiz, testavam-me indagando se eu saberia identificar quem era o designer de uma cadeira à nossa frente ou o autor de um quadro na parede. Ao citar um intelectual que frequentara a casa, indagavam se eu havia lido algum de seus ensaios, ou mesmo se havia visitado certo lugar no exterior, ao falarem de alguma relíquia trazida de viagem. Essas questões vinham principalmente no início, quando eu me apresentava como cientista social. Em uma dessas situações, ao falar que antes de ter cursado Ciências Sociais, eu havia me formado em Arquitetura e Urbanismo na Universidade de São Paulo, o interlocutor respondeu, "ah, então você sabe de tudo isso mais do que eu", revelando que eu poderia ser assimilada na condição de especialista de arquitetura, possivelmente tida até como mais competente e mais legítima do que eles próprios.

Outro ponto que merece ser citado, mas que não será desenvolvido, é a questão de eu ser mulher. Isso certamente facilitou aos entrevistados falarem com maior intimidade de relações familiares, principalmente quando havia questões sensíveis em jogo. Muitos se emocionaram lembrando situações do passado e até choraram, ao recordarem momentos de saudosismo ou frustração familiar. Talvez aqui a condição feminina me desse alguma legitimidade para adentrar em assuntos domésticos, perguntar sobre temas aparentemente leves como escolha de decoração, e a partir daí, adentrar em assuntos como filhos e infância, sem que causasse constrangimentos e relembrasse situações de maior fragilidade, nas quais pareciam acertar as contas com o passado, na nostalgia de quase todo adulto ao evocar, em visão idílica, uma infầncia de bem-nascidos.

\section{Casas modernas e gosto erudito: gênese social do sistema de preferências}

As casas em questão não são moradias convencionais, ou uma moradia qualquer, como se diz quando se quer se distanciar do ordinário e demarcar raridade do gosto. Trata-se de casas que, a partir de diversos critérios objetivos - metragem do terreno, área construída, quantidade e tamanho dos cômodos, qualidade dos acabamentos, preço do imóvel, valor do IPTU e localização urbana - expressam o padrão de consumo material de frações abastadas da elite paulistana. São casas com área construída superiores a $300 \mathrm{~m}^{2}$, localizadas nos bairros mais cotados da cidade. No entanto, o que reafirma a natureza distintiva e a lógica de exclusividade dessas moradias é que, além das características tipicamente ligadas ao acúmulo de recursos econômicos, estão associadas à raridade dos gostos e estilos de vida de uma fração cultivada de elite. 


\section{Patrimônio imobiliário convertido em herança cultural: a casa como espaço de transmissáo do gosto erudito em famílias da elite cultural paulistana}

São projetos arquitetônicos reconhecidos como arquitetura de autor e que, devido à importância dos arquitetos que os conceberam, passaram a fazer parte da história da arquitetura. São casas cujo estilo, forma, agenciamento dos espaços internos, técnica empregada e materiais utilizados fizeram com que fossem classificadas como obras, no sentido de manifestação cultural e artística. Elas foram festejadas, no circuito fechado que une produtores e consumidores - do qual participam diversos agentes culturais, entre os quais, críticos, historiadores, agentes do patrimônio e curadores de exposição - pelo arrojo, inovação, originalidade e vanguardismo, o que se manifesta na reputação angariada pelos arquitetos, que passaram a ser vistos como autores, criadores.

As pessoas que entrevistei, na faixa entre 50 e 60 anos, haviam morado nessas casas durante suas infâncias e adolescências. Relatavam, portanto, a casa construída pelos seus pais. Algumas tinham sido vendidas ainda na infância dos entrevistados, e assim, eles tinham vaga memória dos espaços e das condições da encomenda. Outros, por outro lado, herdaram o patrimônio imobiliário e chegaram a morar na casa com suas próprias famílias, mantendo parte da decoração tal como era a casa dos pais. Outros, ainda que não morassem mais na residência, herdaram móveis, quadros, louças e demais objetos de valor, cuja partilha foi negociada entre irmãos. Um deles ainda residia na moradia, mas declarou-se interessado em vendêla, possivelmente em razão do alto custo de conservação desse tipo de residência, ou alugá-la, uma vez que começam a surgir empresários interessados a instalar nesses espaços empreendimentos comerciais ligados à arte, economia criativa e consumo distintivo ${ }^{5}$.

\section{Morfologia social da clientela da arquitetura erudita}

A morfologia social da clientela da arquitetura moderna paulista é indispensável para compreender a gênese social dos sistemas de preferências. A arquitetura de linhas racionalistas, com volumes geométricos e materiais brutos como o cimento sem revestimento caiu no gosto de frações cultivadas que se consolidaram na São Paulo a partir dos anos 1940. Muitos deles, como mostram os dados colhidos com os entrevistados, eram imigrantes e descendentes de primeira geração de italianos, judeus, poloneses, húngaros e alemães que se instalaram na capital paulista e lograram trajetória de ascensão social, ou pelo comércio ou

5 Essas casas se transformaram, conforme tenho levantado, em cafés gourmets, bistrôs, espaços de coworking, galerias de arte, espaço para exposição de design. Registra-se, também, recentemente o surgimento de imobiliárias especializadas na comercialização de imóveis identificados pela assinatura do arquiteto, ou seja, há a formação de um mercado atrelado a uma demanda específica, interessada em adquirir bens com alto valor cultural. 
investindo na formação escolar. A maioria, vale destacar, não chegou aqui em situação miserável ou desprovido de bens materiais e culturais. Alguns relatam que os avós tinham alguma afeição à cultura moderna, aquisição quando estavam na Europa.

Instalados no país, os descendentes dessas famílias se desenvolveram sobretudo em profissões liberais, intelectuais e artísticas. Os relatos registram a diversidade das profissões dos encomendantes: médicos, jornalistas, advogados, professores universitários, economistas, engenheiros, psicanalistas, fotógrafos, cientistas sociais. Entre eles, observa-se alguns egressos das primeiras turmas das faculdades criadas na Universidade de São Paulo, o que mostra a força da fundação da universidade na formação de uma nova classe média cultivada e interessada em patrocinar a cultura moderna. A formação escolar e atuação profissional lhes facultou o acesso a grupos de vanguarda, colocando-os em contato com diversas atividades culturais, artísticas e políticas da cidade, que se desenvolveram sobretudo em torno de novos museus - Museu de Arte Moderna (MAM) e Museu de Arte de São Paulo Assis Chateaubriand (Masp) - criados no final dos anos de 1940, novos teatros - Teatro Brasileiro de Comédia (TBC) e Cultura Artística - revistas culturais como a Clima e Fundamentos e de partidos ligados a grupos de esquerda mais radical ou moderada - como o Partido Comunista Brasileiro (PCB), Partido Socialista Brasileiro (PSB). Quando intelectuais ou profissionais liberais, muitas vezes estiveram ligados a pautas politicamente engajadas, como defesa da reforma agrária, do direito trabalhista, da saúde pública e do desenvolvimento de um projeto nacional de industrialização.

A proximidade dessas pessoas em um círculo de sociabilidade mais ou menos coeso é evidente nas falas dos filhos, uma vez que muito dos nomes e dos locais de frequentação se repetem entre os entrevistados. Muitos citam que os pais tinham contato com artistas plásticos de destaque nacional, como Candido Portinari, ou artistas em ascensão na capital paulista na época, também ligados aos movimentos modernos, como o Grupo Santa Helena.

As informações sobre a composição social e as redes de amizade dessa clientela mostram que era dotada de diversos trunfos e redes de pertencimento que a colocavam na posição mais ilustrada e cultivada da burguesia paulistana. A própria encomenda da residência com projeto de arquitetos que propalavam a arquitetura moderna é um marcador indicativo das condições sociais e culturais desse grupo. A compra de lotes individuais em bairros residenciais também explicita os valores em relação ao padrão de moradia expressos na qualidade da localização geográfica. Para essa clientela, a boa colocação profissional resultaria em ganhos econômicos decisivos que possibilitaram arcar com a compra de terrenos nos bairros mais nobres da capital paulista - Pacaembu, Perdizes, Morumbi, Jardim Europa, Jardim Paulista, Jardim América, Jardim Guedala -, loteados com plano urbano estrito de 


\section{Patrimônio imobiliário convertido em herança cultural: a casa como espaço de transmissáo do gosto erudito em famílias da elite cultural paulistana}

uso exclusivamente residencial em ruas sinuosas com grande arborização, ocupando as regiões melhores dotadas de infraestrutura e próximas à rede de serviços de qualidade e comércio de média e alta renda.

Foi por meio das relações de amizade que adquiriram telas e esculturas de artistas que despontavam no modernismo e encomendaram móveis de arquitetos e designers favoráveis a linhas retas e despojadas, tomada de posição estética que recusa o uso de ornamento, provavelmente visto como rebuscado, antiquado ou muito próximo dos gostos da antiga oligarquia rural ou da burguesia econômica. Ter uma casa assinada por uma elite de arquitetos reconhecida oficialmente na história da arquitetura é uma exclusividade que diz muito dos clientes que as encomendaram, agentes dotados de condições culturais e financeiras para exprimir com eloquência seus gostos e estilos de vida em espaços que modelam o cotidiano, a família e sua imagem social. Essas casas se apresentam, no limite, como estilo de vida centrado na afirmação de um projeto intelectual e artístico.

Reveladora dessa condição foi a observação aguda proferida por uma entrevistada, socióloga e também moradora de uma residência radicalmente moderna, quando a interroguei a quem, de modo geral, as casas eram destinadas, especificando se ela tinha dados sobre o perfil social do grupo encomendante. Ela afirmou, afiada, era "para quem tinha estirpe".

Mobilizar o termo estirpe, tão ligado ao contexto da genealogia familiar e da transmissão de certo modo refinado e que traz, indubitavelmente, a condição de detentores de posições ligadas a boa cepa, traduz tanto a ideia de privilégio de um grupo, quanto de sua capacidade de conservar o patrimônio por gerações. Se a propriedade residencial exprime visível e duravelmente as condições econômicas, os gostos e a capacidade de apropriação de bens estéticos, nos casos em questão, alguns de seus moradores estão cientes que o projeto da casa com contratação de um arquiteto adepto do modernismo, estilo e profissão recente nos anos 1950, expressa a raridade do consumo de um tipo de serviço especializado, restrito à ínfima parcela da população ${ }^{6}$.

$\mathrm{O}$ investimento financeiro e afetivo em um projeto de arquitetura sob medida, construído em terrenos individuais em áreas urbanas privilegiadas da capital paulista, materializa e especifica as práticas culturais adotadas por esse grupo de clientes. Trata-se de um grupo com capacidade econômica para garantir exclusividade nos seus espaços de moradia e com maior propensão para atribuir à residência um sentido ao ato de morar não apenas técnico e funcional. A escolha do local e tipo de moradia

6 O curso de arquitetura e urbanismo da Universidade de São Paulo se institucionalizou em 1948 e antes dele, em 1947, havia sido criado o curso do Mackenzie. Até então, desde o final do século XIX, existia apenas o curso de engenheiro-arquiteto, oferecido pela Escola Politécnica, que formava uma fração muito pequena dos engenheiros que passavam pela instituição e se direcionavam para o exercício da prática de arquitetura (FICHER, 2005). 
não satisfaz apenas condições básicas de abrigo e conforto, mas está carregada de aspectos simbólicos, que se fazem pela eleição de estilo de arquitetura, pela adoção de um novo arranjo dos espaços internos e pelas preferências autorais na decoração. Essas escolhas, marcadamente artísticas, estiveram guiadas a partir da percepção e a apreciação estética erudita, para a qual há a prerrogativa de originalidade e exclusividade.

O valor cultural pretendido, não por acaso, atesta a predileção pelo novo. Não era, certamente, o mais tradicional e seguro naquele momento, tendo em vista que a maioria dos projetos residenciais em bairros de alta renda eram menos ousados esteticamente. No entanto, a arquitetura moderna, no período entre 1940 e 1960, despontou com a criação das faculdades de arquitetura e se consagrou com a construção de Brasília. O gosto moderno e arrojado comunicava adesão a uma posição progressista e, em alguns casos, audaciosa e politicamente engajada, observado quando vinha acompanhada da crítica ao que os arquitetos acreditavam ser os modos de morar burguês, avaliados como distantes daquilo que propunham.

\section{Habitar numa casa moderna}

Foram citadas pelos entrevistados ou puderam ser identificadas nas fotografias antigas dos imóveis as atividades culturais que neles praticavam, quase sempre associadas ao gosto erudito. Destacam-se a grande frequência de viagens internacionais e aquisição de objetos de decoração e arte, por vezes pela lógica do colecionismo, como peças do barroco brasileiro, quadros de artistas modernos e artefatos tidos como exóticos, populares ou vernaculares (por exemplo, cestarias, colares e carrancas indígenas; vasos e potes marajoaras; redes nordestinas; tapeçarias artesanais). Essas práticas que vinculam gosto a estilo de vida ajudam a localizar o perfil social desse grupo como amantes das artes, conformando uma burguesia ilustrada que amealhou algum dinheiro no exercício de uma profissão garantida pela formação universitária e fez questão de investir em bens e consumos ligados à sua posição cultural.

Entre aqueles que moraram nessas casas apenas na infância, foi realçado o sentimento de nostalgia e tristeza de terem perdido a casa arrojada, que causava estranheza por ser diferente da dos vizinhos e importante do ponto de vista do patrimônio cultural arquitetônico. Lembraram-se, por exemplo, que, quando crianças, era comum desconhecidos baterem à porta pedindo para conhecer a casa, ou amigos da escola ficarem espantados com o espaço doméstico que lhes parecia muito diferente daquele onde moravam. Se alguns mostravam estranhamento, possivelmente os mais leigos, outros, mais instruídos ou com competências técnicas para apreciar o imóvel, mostravam-se interessados. Os entrevistados, especialmente 


\section{Patrimônio imobiliário convertido em herança cultural: a casa como espaço de transmissāo do gosto erudito em familias da elite cultural paulistana}

aqueles que moraram em residências publicadas por muitas vezes em revistas e livros de história da arquitetura, citaram ter sido bastante comum receber jornalistas, fotógrafos, grupos de estudantes de arquitetura, arquitetos formados e estrangeiros motivados a conhecer o projeto arquitetônico. Houve um entrevistado que mostrou com orgulho a coleção de reportagens de jornais e revistas que tiveram como tema a casa de sua família. Outros tinham em suas bibliotecas e mesmo nas mesas de centro da casa livros de história da arte e da arquitetura que apresentavam a obra do arquiteto autor do projeto.

Quando se trata de espaços amplos e esteticamente interessantes, a questão dos usos sociais da casa também foi citada. Ao rememorar a moradia de sua infância e juventude, uma entrevistada abriu o álbum de família para mostrar as fotografias do casamento realizado nos anos 1970 no amplo salão de pé-direito duplo da casa dos pais. Também afirmou que era frequente os pais receberem amigos, realizarem escutas musicais, darem festas para muitas pessoas. Praticamente todos os informantes declararam que os pais eram bons anfitriões e que a casa era ponto de referência em seus círculos de sociabilidade. A originalidade do projeto e a qualidade de seus espaços impulsionavam o interesse da rede de amigos ou servia de chamariz para apresentá-la para algum notável. Entre os mais citados, destaco o historiador e militante comunista Caio Prado Junior, o físico e crítico de arte Mário Schenberg, os pintores Candido Portinari e Alfredo Volpi e os escritores Jorge Amado e Pablo Neruda. Uma das entrevistadas recordou que a casa moderna era ponto de encontro de intelectuais, que se reuniam no grande salão central para ouvir música e debater política, e para marcar a presença dos habitués, na porta de entrada havia um grande quadro onde os amigos e visitantes célebres deixavam suas assinaturas e recados. Também informou a preocupação do pai, tão logo se iniciaram as perseguições na ditadura militar, em destruir a placa, para que não deixassem vestígios da rede de contatos desse grupo de intelectuais engajados.

Posto que a maioria desses encomendantes possuem grande acervo de livros, é patente a importância dada no projeto arquitetônico ao espaço para abrigá-los: eles estão situados em local de destaque da moradia, simbolicamente índice do valor que conferem à leitura e ao trabalho intelectual. Várias das residências apresentam no programa um lugar especialmente projetado para biblioteca e escritório, no entanto, ela não foi instalada em cômodo compartimentado, impermeável ao olhar dos outros. Elas estão em local visível, muitas vezes no centro da casa, em um mezanino ou em um patamar elevado. Por exemplo, na residência de um advogado, a biblioteca é aberta e foi localizada um pavimento intermediário, fazendo ligação entre sala de estar, no primeiro andar, e parte íntima, no segundo andar (quartos e sala de banho). Ela foi situada de tal maneira que se impõe como passagem obrigatória para todos da família. Na residência de um professor universitário, as prateleiras de livros ocupam do piso ao teto a parede lateral de toda a casa, com cerca de 20 
metros de extensão, e estão solenemente iluminadas pela caixilharia em madeira e vidro que preenche a cobertura em abóbodas. Em outra, a biblioteca foi instalada em um escritório envidraçado que ocupa o espaço central do imóvel, onde há um grande jardim aberto. Os exemplos mostram que os livros ordenam a distribuição e uso dos espaços, marcando forte presença na paisagem. Talvez possam se apresentar de modo imponente às visitas, que logo se deparam com grandes coleções que exteriorizam o acúmulo literário dos moradores; no entanto, para os membros da casa, os livros estão o tempo todo à mão, socialização precoce que predispõe a familiaridade que demonstram ter com a cultura legítima.

Por serem pessoas afeitas ao colecionismo, a organização formal da casa, com suas grandes paredes, corredores, rampas ou passarelas funcionava também como espécie de galeria privada que permitia exibir peças de arte. O mobiliário também estava de acordo com o espaço arquitetônico arrojado, quase sempre feito sob medida por designers e ateliês modernos celebrados, entre os quais, Lina Bo Bardi, Zanine Caldas, Sérgio Rodrigues, Branco\&Preto, Mobília Contemporânea (ROSATTI, 2019). Todos os entrevistados informaram o interesse dos pais por arte moderna e alguns alegaram o investimento em adquirir e manter na família um Portinari ou um Volpi.

Sobre o interesse em arte, é reveladora a informação de uma das informantes, moradora de grande apartamento em cobertura. Quando perguntei sobre o gosto artístico e o investimento em obra de arte, ela foi procurar em seu escritório uma listagem manuscrita pelo pai, nos anos 1950, com os quadros modernos que possuía, antes de vendê-los em razão de dívidas, conforme relatou, para salvar a situação econômica desfavorável de amigos e familiares. Mostrou-me os bens que herdou e também aqueles que teria herdado se não fosse a generosidade do pai. Em outra entrevista, um dos herdeiros abriu um arquivo no computador para mostrar o inventário do pai recém-falecido que seria partilhado entre ele e as duas irmãs. A lista continha todos os bens da família, fotografados e catalogados, entre os quais três imóveis residenciais projetados por célebres arquitetos modernos (dois apartamentos e uma casa na fazenda) e uma grande coleção de objetos de design, mobiliário assinado, peças de arte sacra do barroco brasileiro e quadros de diversos artistas brasileiros.

Essas observações extraídas da presença em campo mostram que, para esse grupo com forte lastro cultural, a manutenção de determinados bens artísticos e a circulação entre gerações (passagem de pais para filhos, herança de avôs e tios) funciona como atestado da antiguidade do capital cultural na família, presente não apenas na decoração e nos objetos, como também na linguagem da fala, do corpo, nos modos de se vestir e de me receber. 


\section{Patrimônio e transmissão em família: habitação e habitus cultivado}

No andamento das entrevistas, me chamou a atenção a questão da transmissão do patrimônio, à primeira vista, do imobiliário, concentrado em sua forma material e financeira, mas também o patrimônio simbólico. Tanto para aqueles que a casa havia deixado de pertencer ao patrimônio imobiliário da família quanto para aqueles que ainda moravam nela, o imóvel representaria a continuação do gosto moderno, ou seja, as disposições estéticas em relação ao gosto moderno se perpetuaram a ponto de exercer influência na escolha da casa quando adulta.

Aqui fica claro o jogo mais complexo de transmissão familiar de predisposições e aquisições. Alguns dos entrevistados, mesmo não tendo optado por encomendar e construir nova residência moderna sob medida, tal como fizeram seus pais, procuraram, no momento da formação de sua própria família, comprar apartamento assinado pelo mesmo arquiteto, reconhecendo a qualidade arquitetônica, estética e espacial do imóvel onde moraram na infância. Nesses casos, o que se transmitiu não foi o bem jurídico, mas sobretudo a condição de apropriação de um bem artístico, isto é, a posse dos instrumentos que permitem seu consumo como objeto estético (BOURDIEU, 1979).

Significativo desse caso é o entrevistado que morou na primeira infância em residência projetada por Vilanova Artigas, vendida logo após a separação dos pais, consequência da imposição de partilha dos bens imobiliários. No entanto, as disposições culturais mais amplas da família - evidenciada pela posição do pai, importante advogado, que se tornou militante do Partido Comunista e seguiu carreira de jornalista, sendo responsável por uma das publicações culturais do Partido no período dos anos 1940-1950 - foram adquiridas por um trabalho implícito de inculcação, empreendimento precocemente transmitido e acumulado por muito tempo. A entrevistada declarou ter escolhido morar, na vida adulta, com sua própria família, num apartamento em um edifício residencial projetado pelo mesmo arquiteto. As razões alegadas foram a qualidade formal do imóvel, reconhecida pelas grandes janelas, espaços amplos, e o valor estético da moradia, justificadas pela preferência por linhas sóbrias, modernas e despojadas. Interessada na preservação do patrimônio, ela passou a desempenhar papel de guardiã do edifício: engajou-se nas atividades para gestão do condomínio a fim de preservar a construção original, definiu normas quanto às intervenções, garantindo que as reformas mantivessem cores, materiais e acabamentos originais definidos pelo arquiteto, assim como o desenho dos jardins, os revestimentos do hall de entrada e os painéis artísticos. Conforme me confiou, seu apartamento, diferentemente de muitos outros moradores que alteraram o desenho original para adequá-los a novos usos, ainda conserva a disposição dos espaços tal como o projeto do arquiteto, confirmando seu compromisso, tal como julga, de não o descaracterizar. 
A continuidade das disposições e das aquisições culturais são emblemáticas também na trajetória de outro herdeiro, de cerca de 55 anos, dramaturgo e filho de um engenheiro. Esse entrevistado havia recentemente vendido a residência encomendada pelo pai no final dos anos 1960, local em que ele havia morado com sua própria família logo após casar-se, e comprado um imóvel na região central, local onde ocorreu a entrevista. A organização espacial, o investimento em design contemporâneo e o gosto pelo colecionismo são evidentes em seu apartamento atual, como pude notar pela reforma realizada, que retirou quase todas as paredes de modo a formar amplo espaço na área social. A presença de peças de design também é a marca da residência e se afina com o interesse do pai, que, entre os anos 1950 e 1970, encomendou peças dos melhores ateliês. Em toda lateral do imóvel e contornando outra parede com ampla janela foi instalada imponente biblioteca ondulada com cores em degradê, de cerca de 14 metros, projetada pelo escritório franco-brasileiro Triptyque, um dos mais destacados da nova geração de arquitetura contemporânea ${ }^{7}$.

A monumental e ousada estante, nomeada pelos arquitetos de Treme-Treme, em referência a um dos edifícios símbolos de centro de São Paulo, virou hit entre um público de amantes do design contemporâneo e tem sido encomendada por clientes do meio artístico, como artistas plásticos, estilistas e empresários do setor cultural. Ela é projetada de acordo com o espaço do cliente. Cada uma das prateleiras tem desenho único, com curvatura e ondulação de modo a produzir um movimento sinuoso. No apartamento do entrevistado, que inclusive foi fotografado para revistas de arquitetura, design e decoração, a exuberante estante servia para exposição dos livros de arte e literatura do proprietário, que, como o pai, é colecionador de obras de arte e mobiliário.

Essas duas situações mostram que a aquisição cultural se expressa tanto pelo objeto material herdado, quanto pela aquisição de percepções e competências, tal como se vê na continuidade do gosto moderno. A transmissão cultural a partir da experiência doméstica se manifestou nos modos de vida, nas atitudes e valores internalizados, nas práticas culturais e nas escolhas profissionais dos herdeiros, engajamentos profundos que poderiam ser nomeados de culto à cultura. Para membros de grupos culturalmente privilegiados, que desde a infância tiveram a experiência de habitar em espaços domésticos dotados dos mais prestigiosos bens materiais - livros, obras de arte, mobiliários de design, objetos de coleção, relíquias familiares - o espaço familiar foi definitivo na constituição de discursos e práticas cultivadas.

\footnotetext{
7 O escritório Triptyque foi criado em 2000 por quatro sócios franceses recém-formados que se instalaram no Brasil e abriram a sede em São Paulo.
} 
Patrimônio imobiliário convertido em herança cultural: a casa como espaço
de transmissáo do gosto erudito em famílias da elite cultural paulistana

A área da cultura como escolha profissional

No que se refere às dimensões mais profundas da definição de um estilo de vida, fortemente representada pela escolha profissional, é possível observar entre os pesquisados, quase todos na faixa dos 50 a 70 anos, prevalência da atuação em áreas ligadas ao mundo da arte, cultura e ciência.

As escolhas profissionais dessa geração de herdeiros são significativas para compreender a transmissão de uma relação cultivada com a cultura que orientou as escolhas educacionais e profissionais. Levando em conta o conjunto dos entrevistados, o que se observa é que a força da socialização primária em um ambiente de sofisticação artística se impôs e condicionou escolhas em relação à formação universitária e atuação profissional. Antes disso, vêm as estratégias escolares dos pais, que, ao escolher os colégios para os filhos no período da infância e adolescência, optaram por instituições particulares tradicionais da cidade de São Paulo, como os colégios Dante Alighieri, Bandeirantes, Vera Cruz, Santa Cruz e Equipe, marcadamente ligados a atividades de incentivo cultural. O circuito é reduzido e, não por acaso, alguns dos entrevistados alegaram se conhecer por terem passado pelos mesmos espaços escolares. A trajetória escolar, em seguida, se deu com a entrada em universidades de prestígio, como a Universidade de São Paulo ou em escolas no exterior, como na França, seguida pelo ingresso em carreiras ligadas à produção cultural, intelectual, científica ou social.

Independente da formação que escolheram cursar, acabaram por desempenhar atividades intelectuais no campo da cultura e das artes, muitas vezes em cargos de chefia e liderança, ou compromisso de disseminação do conhecimento ou de portavozes em suas áreas. As profissões e os cargos ocupados eram: escritor, dramaturgo e diretor de peça teatral, economista e professora universitária, psicoterapeuta que possuía coluna na imprensa, psicanalista, filósofo e professor universitário, sociólogo e professor universitário, artista plástico, arquiteto, músico e compositor de jazz, médico pesquisador com carreira internacional, escritora de livro infantil e diretora de importante biblioteca pública estadual, designer gráfico com doutorado na área, proprietário e diretor de organização não governamental com atuação na área social e de meio ambiente; economista e diretor de marketing de time de futebol de primeira divisão em São Paulo.

A possibilidade de seguir esses caminhos não se dá por acaso. Oriundos de frações intelectualizadas de classe média alta, esses filhos herdeiros fizeram investimentos constantes e decisivos ao longo da trajetória escolar. Por se tratar de filhos de famílias com posições mais vantajosas na hierarquia social, a eles estavam disponíveis maiores recursos financeiros e simbólicos para sustentar investimentos em áreas, como as artísticas ou culturais, nas quais a conquista de sucesso ou de retorno financeiro acontece geralmente em longo prazo. 
Quando atuantes diretos na área artística, interessante notar ainda alguns casos em que a história familiar ou a herança da casa é retrabalhada e transformada em produção cultural erudita. Um dos herdeiros, diretor de teatro e cinema, escreveu um livro inspirado na história do pai viúvo e que, conforme relatado, seria adaptado para peça de teatro e filme. Transformando a experiência real vivida pela família, o livro narra de modo divertido e sensível a relação de uma idosa cosmopolita, importante no meio musical erudito, com seu acompanhante e cuidador. Ela, moradora de um grande casarão em bairro nobre de São Paulo, ele, empregado pobre vindo da periferia, estabelecem uma relação de convivência difícil e cômica, com os desentendimentos e peripécias de frequentarem juntos os mais diversos locais culturais refinados de São Paulo e no exterior. O filho herdeiro entrevistado, que havia cursado sociologia nos anos 1970 na França, e depois, sob motivação da família, se encaminhado para a área artística, afirmou que extraía a matéria para sua produção dramatúrgica dos descompassos e atritos entre classes sociais vividos no ambiente doméstico, com a experiência do pai que, quando idoso e doente, estabeleceu uma relação parecida com seu cuidador.

Outro herdeiro, que atua como compositor e músico de jazz, ao me falar sobre suas escolhas profissionais, me ofereceu CD gravado por ele e sua banda. É significativo que a capa e o encarte possuam ilustração que reproduz o painel geométrico presente na fachada da residência, executado, nos anos 1950, por importante artista plástico. A casa é considerada um ícone da arquitetura moderna paulista, reconhecida pela filiação ao movimento concretista e essa intervenção gráfica, um grande painel azul e branco cortado por várias diagonais, é comumente utilizada por historiadores e críticos para se referirem à residência. $\mathrm{O}$ disco, como se pode notar pelo título e pelas letras das músicas, explora a relação entre arquitetura e música, entre arte concreta e arte sensível, algumas das quais fazendo referência a obras literárias e lugares poéticos, o que reforçam a erudição e o lastro afetivo do empreendimento artístico.

A complexidade da transmissão cultural tem nesses dois casos uma de suas muitas expressões. O que vale destacar é que legando para a sociedade dois artistas, dois agentes da cultura erudita, um músico e outro escritor e dramaturgo, as elites culturais contribuem para reproduzir suas percepções estéticas como produção cultural, muitas das quais diretamente ligadas a suas histórias pessoais e familiares. Aí se vê também que patrimônio e memória familiar são reapropriados e utilizados para afirmação de seus projetos artísticos, fazendo uso do patrimônio adquirido e ampliando a legitimidade simbólica de que já dispõem. 


\section{Patrimônio imobiliário convertido em herança cultural: a casa como espaço de transmissão do gosto erudito em famílias da elite cultural paulistana}

\section{Considerações finais: herdar uma relação cultivada com a cultura}

A pesquisa focalizou os encomendantes, para os quais o projeto da casa moderna foi inicialmente direcionado, e os filhos, que nelas moraram quando crianças. Tendo como horizonte de investigação as estratégias de transmissão intergeracional e de distinção cultural, este estudo apurou de que modo as escolhas em matéria de moradia estão associadas às formas de dominação de certas frações de classe, notadamente, grupos bem situados em posições de prestígio propriamente cultural.

As informações sobre a composição social e as relações de amizade dessa clientela mostram que ela era dotada de diversos trunfos e redes de pertencimento que a colocavam na posição mais ilustrada e cultivada da burguesia paulistana. As casas de exceção - aqui tratadas como via de acesso privilegiado a grupos que são comumente fechados e que estão menos dispostos a revelarem suas práticas culturais, consumos artísticos, formas de organização, decisões em relação à herança etc. - orientaram estratégias de conservação do patrimônio e de reprodução familiar. Com essa entrada empírica, foi possível tratar do processo de aquisição de uma relação estética com a cultura, em que a casa passa a ser declaração visível do sucesso e do volume global de capital cultural do proprietário e sua família.

Esses bens imobiliários, valorizados pelo atributo artístico e pela proeza arquitetônica, fornecem imagem bastante representativa dos investimentos patrimoniais feitos por frações da classe dominante que acumulam capitais econômicos e estão situados no topo da hierarquia cultural. Procurou-se mostrar de que forma a transmissão cultural realizada no seio familiar, mais especificamente, no espaço doméstico, está atrelada a escolhas que incidem em domínios expressivos da vida social. Nesse caso, os locais de moradia (bairros exclusivos), os modos e as maneiras de habitar (as escolhas modernas em matéria de decoração, a adoção de estilos arquitetônicos e os cuidados em relação à organização desse espaço) compõem um universo de escolhas distintas e distintivas que reafirmam a notável capacidade desses proprietários de coincidirem suas preferências com a imagem social com a qual querem se representar.

Trata-se, portanto, da questão ampla da transmissão do patrimônio, que envolve tanto a herança imobiliária, quanto da habitação enquanto espaço de incorporação do habitus cultivado. O que se nota é que em geral a encomenda da casa demarca um projeto de fundação familiar, iniciado com o matrimônio e com a chegada dos filhos, e com ela se estabelece certa coesão e adesão entre os membros da família que se multiplica nas práticas e discursos, ou seja, nos gostos, em geral.

A investigação mostra que a casa é catalisadora de experiências que agregam a família e, mais largamente, o grupo em que estão inseridos. Uma das marcas mais evidentes da transmissão foi que, ao longo da entrevista, os informantes 
recordaram fatos, relataram causos ou foram buscar em seus armários os traços da transmissão do patrimônio cultural e material dos pais e de seus filhos. Além de bens de decoração como móveis, louças, vitrais, quadros, apontados como recordações, mostraram álbuns de família, viagens, casamento e registros fotográficos do momento da construção da casa, ocasião que serviu para tecerem comentários sobre o esforço, a exclusividade e a aventura do investimento dos pais. Em alguns casos, os entrevistados mostraram obras de arte e móveis herdados, e que agora decoravam suas próprias casas. Nessas ocasiões, sempre ressaltavam o nome, dando ênfase ao estatuto autoral da peça, indicando condições de aquisição, que se tratava, como pude constatar, na maioria das vezes de produtores em proximidade com as redes de sociabilidade da família, sendo que nessas a mãe é citada como parte atuante do projeto ou, em poucos casos, menos interessada.

Ainda sobre a importância do culto à assinatura e seus reveses, quando acrescentei a informação que lhes era desconhecida de que o paisagismo da moradia tinha sido projetado por um célebre artista plástico brasileiro, umas das lideranças da arte concreta, eles se mostraram admirados e gratos por partilhar mais uma referência ilustre sobre a moradia. No entanto, confiaram, modestamente, que tinham alterado todo o jardim. Expõem, assim, o limite de suas competências e aquisições, reconhecendo neles a condição mais de amadores, amantes par défaut, do que de especialistas, pois a introjeção desses conhecimentos artísticos se deu pela socialização doméstica, não por aprendizagem sistemática ou pesquisa científica, portanto, não baseada em competência específica.

De todo modo, as escolhas estéticas dessas frações culturalmente bemnascidas, embora se apresentem como manifestações do terreno do bom gosto, são também escolhas morais e hierarquizantes que preservam vantagens sociais ao longo de gerações, perpetuando de modo mais direto e sutil padrões de excelência social, a partir dos quais os indivíduos se reconhecem entre si e se demarcam dos outros, enquanto sujeitos e coletividade. Para aqueles que detêm os códigos de reconhecimento, essas escolhas são índices preciosos que permitem aproximar semelhantes e excluir aqueles considerados indignos de pertencerem ao grupo.

\section{REAL ESTATE HERITAGE CONVERTED INTO CULTURAL HERITAGE: THE HOUSE AS A SPACE OF TRANSMISSION OF THE ERUDITE taste in families of São PaUlo's cultural elites}

ABSTRACT: This article investigates the transmission of cultural heritage among members of elite families whose parents were commissioners of "author's architecture" houses, i.e., designed by architects recognized and 
Patrimônio imobiliário convertido em herança cultural: a casa como espaço de transmissão do gosto erudito em famílias da elite cultural paulistana

valued for their signature. Based primarily on a set of interviews with their children, we sought to restore the dynamics of acquisition and conservation of the various capitals within these groups. The analysis of cases allows us to expose the continuity of the cultural transmission and the artistic taste from the domestic experience. For these members of culturally privileged groups, who since childhood have had the experience of living in domestic spaces endowed with the most prestigious material resources such as books, works of art, design furniture, objects of collection and family relics, the house was a space which constituted a cultivated relationship with the culture. The erudite cultural heritage is manifested in the most diverse domains of life, in the body hexis and in internalized values, in cultural practices and professional choices.

KEYWORDS: Elites. Housing. Erudite Taste. Heritage.

\section{PATRIMONIO INMOBILIARIO CONVERTIDO EN PATRIMONIO CULTURAL: LA CASA COMO ESPACIO DE TRANSMISIÓN DEL GUSTO ERUDITO EN LAS FAMILIAS de las élites culturales de São PaUlo}

RESUMEN: Este artículo investiga la transmisión del patrimonio cultural entre miembros de familias de élite cuyos padres han encargado casas de "arquitectura de autor", es decir, diseñadas por arquitectos reconocidos y valorados por su firma. Basándose principalmente en una serie de entrevistas con los hijos, se buscó interpretar la dinámica de adquisición y conservación de los diversos capitales dentro de estos grupos. El análisis de los casos nos permite investigar la continuidad de la transmisión cultural y el gusto artístico a partir de la experiencia doméstica. Para estos miembros de grupos culturalmente privilegiados, que desde la infancia han vivido en espacios domésticos dotados de los más prestigiosos recursos materiales - libros, obras de arte, muebles de diseño, objetos de colección, reliquias familiares-, la casa es espacio constituyente de una relación cultivada con la cultura. El patrimonio cultural erudito se manifiesta en los más diversos ámbitos de la vida, héxis corporal y valores interiorizados, las prácticas culturales y las opciones de carreras.

PALABRAS CLAVE: Elites. Vivienda. Gusto erudito. Herencia. 


\section{REFERÊNCIAS}

ALMEIDA, Ana Maria; CANEDO, Letícia e GARCIA, Afrânio. Circulação internacional e formação intelectual das elites brasileiras. Campinas: Editora da Unicamp, 2004.

ALMEIDA, Ana Maria de \& NOGUEIRA, Maria Alice. A escolarização das elites: um panorama internacional da pesquisa. Petrópolis: Vozes, 2002.

BOURDIEU, Pierre. A Distinção. Crítica social do julgamento. São Paulo: EDUSP; ZOUK, 2007.

As estruturas sociais da economia. Porto: Campo das Letras, 2006.

A casa kabyle ou o mundo às avessas. Cadernos de Campo, São Paulo, v. 8, n. 8, p.147-159, 1999.

. Apêndice: O espírito da família. In: . Razões Práticas. Campinas, SP: Papirus, 1996.

. À propos de la famille comme catégorie réalisée. Actes de la recherche en sciences sociales, $\mathrm{n}^{\circ} 100$, p.32-36, 1993.

. Un placement de père de famille. La maison individuelle, spécificité du produit et logique du champ de production. Actes de la Recherche en Sciences Sociales, n. 81/82, 1990.

. Les trois états du capital culturel. Actes de la Recherche en Sciences Sociales. Vol. 30, L'institution scolaire, novembre, p.3-6, 1979.

BOURDIEU, Pierre \& DELSAUT, Yvette. Le couturier et sa griffe: contribution à une théorie de la magie. Actes de la recherche en sciences sociales. Vol. 1, n¹, p.7-36 janvier 1975. (Hiérarchie sociale des objets).

BRAUDEL, Fernand. Civilização material, economia e capitalismo, séculos XV-XVIII. Estruturas do Cotidiano. São Paulo: Martins Fontes, 2005.

CHARLE, Christophe. Como anda a história social das elites e da burguesia? Tentativa de balanço crítico da historiografia contemporânea. In: HEINZ, F. M (org.). Por outra história das elites. Rio de Janeiro: Editora FGV, 2006.

CORADINI, Odaci Luiz. Em nome de quem? Recursos sociais no recrutamento de elites políticas. Rio de Janeiro: Relume-Dumará, 2001.

CERTEAU, Michel de. A invenção do cotidiano. Morar, Cozinhar. Rio de Janeiro: Vozes, 2013. 
Patrimônio imobiliário convertido em herança cultural: a casa como espaço de transmissāo do gosto erudito em famílias da elite cultural paulistana

DURAND, José Carlos. Arte, privilégio e distinção: artes plásticas, arquitetura e classe dirigente no Brasil, 1855/1985. São Paulo: Perspectiva: Edusp, 1989.

ELIAS, Norbert. Sociedade de Corte. Rio de Janeiro: Zahar, 2001.

FICHER, Sylvia. Os arquitetos da Poli: ensino e profissão em São Paulo. São Paulo: EDUSP, 2005.

FREYRE, Gilberto. Casa-Grande e Senzala: formação da família brasileira sob regime patriarcal. 51ª Edição. Rio de Janeiro: Global, 2006.

. Sobrados e Mucambos: decadência do patriarcado rural e desenvolvimento urbano. $15^{\text {a }}$ ed. revista. São Paulo: Global, 2004.

GRYNSZPAN, Mário e GRILL, Igor Gastal. Elites: recursos e legitimação. Revista Pós Ciências Sociais, v8, n15, 2011.

HEINZ, Flávio M. et al. Por outra história das elites. Rio de Janeiro: Editora FGV, 2006.

HOMEM, Maria Cecília Naclério. O palacete paulistano e outras formas urbanas de morar da elite cafeeira: 1967-1918. São Paulo: Editora Martins Fontes, 2010.

LE WITA, Béatrix. Ni vue ni connue: aproche ethnographique de la culture bourgeois. Paris, Éditions de la Maison des sciences de l'homme, 1988.

LIMA, Diana Nogueira de Oliveira. Ethos emergente: as pessoas, as palavras e as coisas. Horizontes Antropológicos, v. 28, p.175-202, 2007.

MACIEL, Louise Claudino. Pode entrar: manifestações de gosto no âmbito da moradia e da decoração das elites culturais na Região Metropolitana de Recife. Tese (Doutorado). Centro de Filosofia e Ciências Humanas da Universidade Federal de Pernambuco, 2018.

MENSION-RIGAU, Eric. L'enfance au chatêau. L'education familiale des élites françaises au 20e sicècle. Paris-Marseille, Rivages, 1990.

MICELI, Sergio. Imagens negociadas: retratos da elite brasileira. São Paulo: Companhia das Letras, 1996.

MONTEIRO, Nuno Gonçalo. O crepúsculo dos grandes: a casa e o patrimônio da aristocracia em Portugal (1750-1832). Lisboa: Imprensa Nacional/ Casa da Moeda, 1998.

PINÇON, Michel; PINÇON-CHARLOT, Monique. Châteaux et Châtelains. Les siècles passent, les symbole demeure. Paris: Éditions Anne Carrière, 2005.

. Sociologia da alta burguesia. Sociologias. Porto Alegre, n. 18, p.22-37, dezembro,

2007.

. Sociologie de la bourgeoisie. Paris, La Découverte, 2009. 
PULICI, Carolina. O charme indiscreto do gosto burguês paulista: estudo sociológico da distinção social em São Paulo. 328p. Tese (Doutorado). FFLCH-USP, 2010.

PULICI, Carolina; FERNANDES, Dmitri Cerbonccini (org). As lógicas sociais do gosto. São Paulo: Editora Unifesp, 2019.

ROCHE, Daniel. História das Coisas Banais: nascimento do consumo nas sociedades do século XVII ao XIX. Rio de Janeiro, Rocco, 2000.

ROSATTI, Camila Gui. Moderno sob medida: produtores e clientelas do mobiliário paulistano nos anos 1950, In: PULICI, Carolina; FERNANDES, Dmitri Cerbonccini (org). As lógicas sociais do gosto. São Paulo: Editora Unifesp, 2019.

. Casas burguesas, arquitetos modernos: condições sociais de produção da arquitetura paulista. Tese (Doutorado). FFLCH-USP, 2016.

SAINT MARTIN, Monique de. Coesão e diversificação: os descendentes da nobreza na França, no final do século XX. Mana, Rio de Janeiro, v.8, n.2, p.127-149, 2002.

TRIGO, Maria Helena Bueno. Os paulistas de quatrocentos anos: Ser e Parecer. São Paulo: Annablume, 2001.

Recebido em 11/03/2019.

Aprovado em 29/04/2019. 